\title{
Neuroendocrine characterization and anorexigenic effects of telmisartan in diet- and glitazone-induced weight gain
}

\author{
Gregory Aubert ${ }^{\mathrm{a}}$, Michel Burnier ${ }^{\mathrm{b}}$, Abdul Dulloo $^{\mathrm{c}}$, Christine Perregaux ${ }^{\mathrm{b}}$, \\ Lucia Mazzolai $^{\mathrm{d}}$, François Pralong ${ }^{\mathrm{a}}$, Anne Zanchi ${ }^{\mathrm{b}, *}$ \\ ${ }^{a}$ Service of Endocrinology, Diabetology and Metabolism, Department of Medicine, Lausanne University Hospital, Centre Hospitalier Universitaire Vaudois, \\ Lausanne 1011, Switzerland \\ ${ }^{\mathrm{b}}$ Service of Nephrology, Department of Medicine, Lausanne University Hospital, Centre Hospitalier Universitaire Vaudois, Lausanne 1011, Switzerland \\ ${ }^{\mathrm{c}}$ Division of Physiology, University of Fribourg 1700, Switzerland \\ ${ }^{\mathrm{d}}$ Service of Vascular Medicine, Department of Medicine, Lausanne University Hospital, Centre Hospitalier Universitaire Vaudois, Lausanne 1011, Switzerland
}

\begin{abstract}
Telmisartan is an angiotensin II receptor blocker with peroxisome proliferator-activated receptor- $\gamma$ agonistic properties. Telmisartan prevents weight gain and decreases food intake in models of obesity and in glitazone-treated rodents. This study further investigates the influence of telmisartan and pioglitazone and their association on weight gain and body composition by examining their influence on neuroendocrine mediators involved in food intake. Male C57/Black 6 mice were fed a high-fat diet, weight matched, and randomized in 4 treatment groups: vehicle, pioglitazone, telmisartan, and pioglitazone-telmisartan. Weight gain, food and water intake, body composition, plasma leptin levels, and the hypothalamic expression of neuroendocrine mediators were analyzed. Additional studies were performed with irbesartan and in angiotensin II $1_{\mathrm{A}}$ receptor-knockout mice. Telmisartan abolished weight and fat gain in vehicle- and pioglitazone-treated mice while decreasing food intake, the hypothalamic expression of the agouti-related protein, and plasma leptin levels. Modifications in neuropeptide $\mathrm{Y}$ and proopiomelanocortin were not consistent with changes in food intake. The effects on weight gain and expression of the agouti-related protein were intermediate with irbesartan. The effects of telmisartan on weight gain were even more pronounced in angiotensin II $1_{\mathrm{A}}$ receptor-knockout mice. This study confirms the anorexigenic effects of telmisartan in mice fed a high-fat diet and suggests for the first time a functional role of telmisartan on hypothalamic orexigenic agouti-related protein regulation. These anorexigenic properties abolish both weight gain and body composition modifications in fat-fed and glitazone-treated mice. The anorexigenic properties are independent from the angiotensin $\mathrm{II} 1_{\mathrm{A}}$ receptor.
\end{abstract}

\section{Introduction}

Telmisartan is an angiotensin II receptor antagonist currently used as an efficient long-duration antihypertensive agent [1]. Although its use in clinical practice is principally to decrease blood pressure, in vitro studies have demonstrated that telmisartan may have additional effects beyond

\footnotetext{
* Corresponding author. Division of Nephrology, Rue du Bugnon 17, CHUV, 1011 Lausanne, Switzerland. Tel.: +41 2131411 54; fax: +41 21 3147001.

E-mail address: azanchidel@hotmail.com (A. Zanchi).
}

its antihypertensive properties [2]. Some structural similarities between telmisartan and pioglitazone led to the hypothesis and demonstration that telmisartan interacts with the peroxisome proliferator-activated receptor (PPAR) $-\gamma$ receptor [3]. In vitro, telmisartan displays roughly a third of the PPAR- $\gamma$ agonist activity of pioglitazone or rosiglitazone [3-5], an effect independent from the AT-1 receptor. In vivo, telmisartan decreases indexes of insulin resistance in some models of insulin resistance $[3,4]$, a finding confirmed by short-term studies in insulin-resistant hypertensive subjects [6,7]. These properties were not attributed to a class effect, as they were not observed with some other angiotensin II receptor antagonists such as valsartan [8] or losartan [3]. 
A very important observation is that, despite its PPAR- $\gamma$ properties that induce adipocyte differentiation, telmisartan is not associated with weight gain [5]. In contrast, the PPAR$\gamma$ agonistic properties of rosiglitazone and pioglitazone are associated with a substantial gain in weight mainly through the generation of metabolically active adipocytes. This is a burden for patients treated with these agents that can negatively influence their prescription. Recently, we demonstrated that telmisartan attenuates the weight gain in rodents fed a high-fat diet and treated with pioglitazone without interfering with the insulin-sensitizing properties of pioglitazone [9]. Although there may be several mechanisms involved, decreased food intake has been observed in different settings with telmisartan and could be a very important contributor to reduction in weight gain $[9,10]$.

The goal of this study was to investigate the influence of telmisartan and pioglitazone and their association on weight gain, body composition, and neuroendocrine mediators involved in food intake in a mouse model of dietary fatinduced obesity. In addition, the effects of telmisartan were compared with those of irbesartan, another angiotensin II receptor antagonist known to have intrinsic PPAR- $\gamma$ agonistic properties [4]. To explore whether the effects of telmisartan were dependent on an intact angiotensin II $1_{\mathrm{A}}$ receptor $\left(\mathrm{AT}-1_{\mathrm{A}}\right)$, knockout $(\mathrm{KO})$ mice for the $\mathrm{AT}-\mathrm{1}_{\mathrm{A}}$ receptor were studied.

\section{Materials and methods}

Male C57/Black 6 mice (Charles River Laboratories Iffa Credo, Lyon, France), aged 8 weeks, had ad libitum access to water and to a high-fat diet consisting (by energy) of $45 \%$ fat, $34 \%$ carbohydrates, and 21\% protein (Diet 2126; Provimi Kliba, Cossonay, Switzerland). All animals were caged singly in a temperature-controlled room $\left(22^{\circ} \mathrm{C} \pm 1^{\circ} \mathrm{C}\right)$ with a 12-hour light/dark cycle.

\subsection{Experiment 1}

After 10 weeks of treatment with the high-fat diet, mice were matched for weight and randomized to the 4 treatment groups: vehicle, pioglitazone $(20 \mathrm{mg} /[\mathrm{kg} \mathrm{d}])$, telmisartan $(5$ $\mathrm{mg} /[\mathrm{kg} \mathrm{d}])$, and pioglitazone-telmisartan $(\mathrm{n}=6$ in each group) for 6 weeks. Pioglitazone was incorporated in the diet $(0.24 \mathrm{~g} / \mathrm{kg})$, and telmisartan was added in drinking water at a concentration of 0.025 to $0.1 \mathrm{~g} / \mathrm{L}$ to match an average intake of $5 \mathrm{mg} /(\mathrm{kg} \mathrm{d})$. Food intake, water intake, and body weight were measured every 1 to 3 days.

\subsection{Experiment 2}

To examine the specificity of telmisartan on changes in body composition, additional male C57/Black 6 mice aged 8 weeks were treated with telmisartan $(5 \mathrm{mg} /[\mathrm{kg} \mathrm{d}], \mathrm{n}=8)$, irbesartan $(100 \mathrm{mg} /[\mathrm{kg} \mathrm{d}], \mathrm{n}=8)$, and vehicle $(\mathrm{n}=7)$ following the identical protocol as above. Irbesartan was added in drinking water to match an average intake of 100 $\mathrm{mg} /(\mathrm{kg} \mathrm{d})$.

\subsection{Experiment 3}

To examine whether the effects of telmisartan were dependent of the AT-1 receptor, angiotensin $\mathrm{II} 1_{\mathrm{A}}$ receptor$\mathrm{KO}$ mice $\left(\mathrm{B} 6.129 \mathrm{P} 2-\mathrm{Agtr} 1^{\mathrm{tm} 1 \mathrm{Unc}} / \mathrm{J}\right)$ were treated with telmisartan $(5 \mathrm{mg} /[\mathrm{kg} \mathrm{d}], \mathrm{n}=8)$ or vehicle $(\mathrm{n}=7)$ following the identical protocol as above.

Body composition and hypothalami were examined in all treated wild-type mice. At the end of the treatment period, animals were killed by decapitation for the determination of body composition. Arterial blood was collected for biochemical analysis in the telmisartan- and pioglitazonetreated mice. Hypothalami were removed and flash-frozen in liquid nitrogen. The headless carcasses were dried to a constant weight in an oven maintained at $70^{\circ} \mathrm{C}$ and subsequently homogenized. Samples of the homogenized carcass were analyzed in triplicate for fat content by the Soxhlet extraction method [11]. Total body water was calculated from the difference between body weight and carcass dry weight, whereas fat-free dry mass (a proxy for body protein mass) was calculated from the difference between carcass dry weight and carcass fat [12].

To exclude a deleterious effect of telmisartan on the wellbeing of mice, a subgroup of male C57/Black 6 mice aged 8 weeks was treated with telmisartan and vehicle at the same doses as above ( $\mathrm{n}=5$ in each group) and separated individually in cages with a running wheel able to measure the total distance performed by each mouse over 25 days. Results were expressed as total kilometers performed on the running wheel.

\subsubsection{Reverse transcriptase polymerase chain reaction}

Hypothalami were homogenized at $4^{\circ} \mathrm{C}$, and total RNA was extract using RNAeasy extraction kit (Qiagen, Hombrechtikon, Switzerland). First-strand complementary DNA was synthesized from $1 \mu \mathrm{g}$ of RNA and random primer in a $20-\mu \mathrm{L}$ reaction volume using random primer and SuperScript II (Invitrogen, Carlsbad, CA) according to the manufacturer's instructions. Relative expression of neuropeptide Y (NPY), proopiomelanocortin (POMC), agouti-related protein (AgRP), and $\beta 2$-microglobulin (reference gene) was then assessed by real-time polymerase chain reaction using the LightCycler technology (Roche Diagnostics, Rotkreuz, Switzerland) with the Takara SYBR Green (Takara Bio Inc, Shiga, Japan). Complementary DNAs of interest were amplified using the following specific primers synthesized by Microsynth (Windish, Switzerland): sNPY (5'-tccgctctgcgacactacat-3') and asNPY ( $5^{\prime}$-tgtttccttcattaagaggtctga- $\left.3^{\prime}\right)$, sPOMC ( $5^{\prime}$-catcttgtccccagagagc- $\left.3^{\prime}\right)$ and asPOMC ( $5^{\prime}$-atggaggtctgaagcaggag- $\left.3^{\prime}\right)$, $\mathrm{s} \beta 2$-microglobulin $\left(5^{\prime}\right.$-cacccccactgagactgataca- $\left.3^{\prime}\right)$ and as $\beta 2$ microglobulin (5'-cgatcccagtagacgctcttg- $\left.3^{\prime}\right)$, and sAgRP (5'accttagggaggcacctcat- $3^{\prime}$ ) and asAgRP (5'-agcaacattgcagtcagcat- $\left.3^{\prime}\right)$. All samples were quantified in at least 2 runs to obtain an interassay coefficient of variation less than $10 \%$, and a 
negative control reaction in the absence of template was always added for each primer pair. Relative expression was then determined using crossing point values and amplification efficiencies of the target gene and the reference gene.

\subsection{Biochemical measurements}

Blood glucose levels were determined with the Glucometer Elite XL (Bayer, Basel, Switzerland). Plasma insulin was determined by enzyme-linked immunosorbent assay (ELISA) (Rat/Mouse Insulin ELISA Kit; LINCO Research, St Charles, MO). Plasma leptin was measured by ELISA (Mouse Leptin ELISA Kit, LINCO Research). Insulin resistance index at baseline was assessed by homeostasis model assessment (HOMA-IR) [13].

\subsection{Statistical analysis}

Data are expressed as means \pm SEM. The statistical significance of differences between the treatment groups was evaluated by analysis of variance (ANOVA) (Minitab, State College, PA) followed by Fisher test for multiple comparisons. A level of $P<.05$ was considered statistically significant.

Procedures used in this study were in accordance with principles of animal care and according to the institutional guidelines. The protocol was reviewed and approved by an independent ethical committee for animal research.

\section{Results}

\subsection{Glucose, insulin, and HOMA-IR}

Plasma glucose, insulin, and HOMA-IR levels decreased slightly but not significantly with pioglitazone and telmisartan in different treatment groups (Table 1).

\subsection{Weight, total food intake, water intake, and HOMA-IR}

Pioglitazone-treated mice increased rapidly their body weight, which remained significantly higher than vehicletreated mice. Telmisartan significantly prevented the increase in body weight induced by the high-fat diet in vehicle- or pioglitazone-treated mice. The weights were equivalent with telmisartan whether vehicle or pioglitazone treated. Telmisartan significantly decreased to the same extent the total food intake in vehicle- or pioglitazone-treated

Table 1

Glucose insulin levels in different treatment groups (experiment 1)

\begin{tabular}{llll}
\hline Group & Glucose $(\mathrm{mmol} / \mathrm{L})$ & Insulin $(\mathrm{U} / \mathrm{mL})$ & HOMA-IR \\
\hline Vehicle & $10.7 \pm 0.6$ & $1.0 \pm 0.2$ & $0.46 \pm 0.08$ \\
Telmisartan & $9.7 \pm 0.4$ & $0.72 \pm 0.19$ & $0.32 \pm 0.08$ \\
Pioglitazone & $9.2 \pm 0.3$ & $0.67 \pm 0.11$ & $0.27 \pm 0.04$ \\
Pioglitazone-telmisartan & $10.7 \pm 0.4$ & $0.65 \pm 0.13$ & $0.29 \pm 0.05$ \\
ANOVA & $\mathrm{NS}$ & $\mathrm{NS}$ & $\mathrm{NS}$ \\
\hline
\end{tabular}

NS indicates not significant.
Table 2

Weight, total food intake, total water intake, and HOMA at the end of experiment

\begin{tabular}{|c|c|c|c|c|}
\hline & $\begin{array}{l}\text { Initial } \\
\text { weight }(\mathrm{g})\end{array}$ & $\begin{array}{l}\text { Final } \\
\text { weight }(\mathrm{g})\end{array}$ & $\begin{array}{l}\text { Food } \\
\text { intake }(\mathrm{g})\end{array}$ & $\begin{array}{l}\text { Water } \\
\text { intake }(\mathrm{g})\end{array}$ \\
\hline \multicolumn{5}{|l|}{ Experiment 1} \\
\hline Vehicle & $28.4 \pm 1.0$ & $30.8 \pm 0.9$ & $104 \pm 6.4$ & $172.8 \pm 15.2$ \\
\hline Telmisartan & $28.5 \pm 0.9$ & $27.2 \pm 1.1^{*, \dagger}$ & $91 \pm 3.1^{* \dagger}$ & $247.7 \pm 14.6^{*}$ \\
\hline Pioglitazone & $28.5 \pm 0.7$ & $32.8 \pm 0.7^{*}$ & $105.5 \pm 1.0$ & $171.9 \pm 5.3$ \\
\hline $\begin{array}{l}\text { Pioglitazone- } \\
\text { telmisartan }\end{array}$ & $28.5 \pm 0.6$ & $26.9 \pm 1.0^{*, \dagger}$ & $90.5 \pm 2.7^{* \dagger}$ & $247.3 \pm 6.2^{*, \dagger}$ \\
\hline ANOVA & NS & $<.001$ & .015 & $<.001$ \\
\hline \multicolumn{5}{|l|}{ Experiment 2} \\
\hline Vehicle & $31.5 \pm 1.2$ & $35 \pm 1.6$ & $105.9 \pm 5.1$ & $191.5 \pm 3.4$ \\
\hline Irbesartan & $30.9 \pm 0.7$ & $30.5 \pm 1.6^{*}$ & $100.5 \pm 9.2$ & $215.9 \pm 12$ \\
\hline Telmisartan & $31.0 \pm 1.2$ & $28.2 \pm 0.5^{*}$ & $92.5 \pm 5.9^{*}$ & $238.9 \pm 15^{*}$ \\
\hline ANOVA & NS & .005 & .048 & .03 \\
\hline \multicolumn{5}{|l|}{ Experiment 3} \\
\hline Vehicle KO & $36.4 \pm 0.8$ & $39.7 \pm 1.4$ & $127.3 \pm 4.2$ & $199 \pm 10$ \\
\hline $\begin{array}{l}\text { Telmisartan } \\
\text { KO }\end{array}$ & $37.8 \pm 0.9$ & $32.8 \pm 1.0^{*}$ & $112.8 \pm 2.7^{*}$ & $301 \pm 23^{*}$ \\
\hline$t$ Test & NS & .001 & .01 & .002 \\
\hline
\end{tabular}

mice. Food intake was strongly correlated to final weight gain $\left(R^{2}=56.5 \%, P<.001\right)$. Telmisartan significantly increased water intake in vehicle- and pioglitazone-treated mice $(P<.001)$. Pioglitazone did not have any effect on water intake (Table 2, Figs. 1-3).

The effects of irbesartan on weight and food intake were intermediate to those of telmisartan. Weights were significantly lower in irbesartan-treated mice than in vehicletreated mice but remained slightly higher than in telmisartantreated mice.

The effects of telmisartan on weight changes were rapid, sustained, and significant in angiotensin II $1_{\mathrm{A}} \mathrm{KO}$ mice. Food intake decreased significantly with telmisartan in $\mathrm{KO}$ mice.

\subsection{Body composition}

Final weight correlated strongly with fat and dry weight $\left(R^{2}=90.2 \%, P<.001\right.$ and $R^{2}=94 \%, P<.001$, respectively) but not with water content $\left(R^{2}=55.8 \%, P>.05\right)$. Pioglitazone-induced weight gain was due not to an increase in water but to an increase in fat weight. Telmisartan decreased very significantly fat weight in vehicle- and pioglitazone-treated mice while increasing fat-free lean mass. Differences in the 2 protocols are due to the fact that the mice were heavier at the beginning of the study in the second protocol. Irbesartan effects on body composition were intermediate to those of telmisartan (Table 3).

\subsection{Neuroendocrine mediators}

Plasma leptin levels were correlated with weight $(P<$ $.05)$ and were lower in telmisartan-treated groups (ANOVA: 


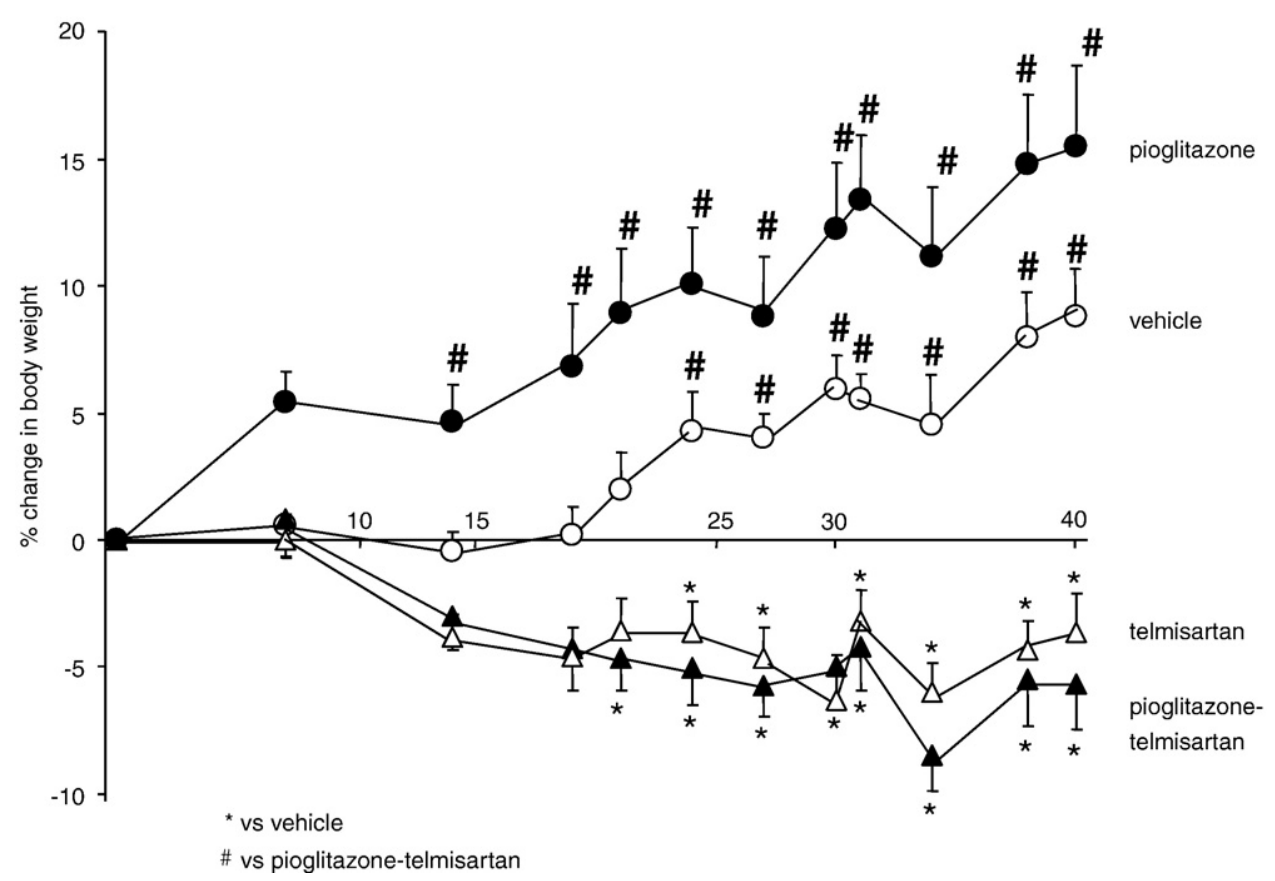

Fig. 1. Experiment 1: percentage change in body weight from baseline in vehicle-, telmisartan-, pioglitazone-, and pioglitazone-telmisartan-treated mice. ${ }^{*} P<.05$.

$P<.01)$. Telmisartan significantly prevented the increase in plasma leptin level induced by pioglitazone $(P<.05)$. The NPY levels increased significantly in the pioglitazonetelmisartan group. The POMC levels were not influenced by telmisartan or pioglitazone. Telmisartan induced a significant decrease in AgRP expression in vehicle- and pioglitazone-treated animals $(P<.05)$. In Fig. 4, results were pooled together from experiments 1 and 2 and expressed as percentage variation from control $(100 \%)$. Expression of the AgRP with telmisartan remained significantly lower than controls, and effects of irbesartan were intermediate (Table 4, Fig. 4).

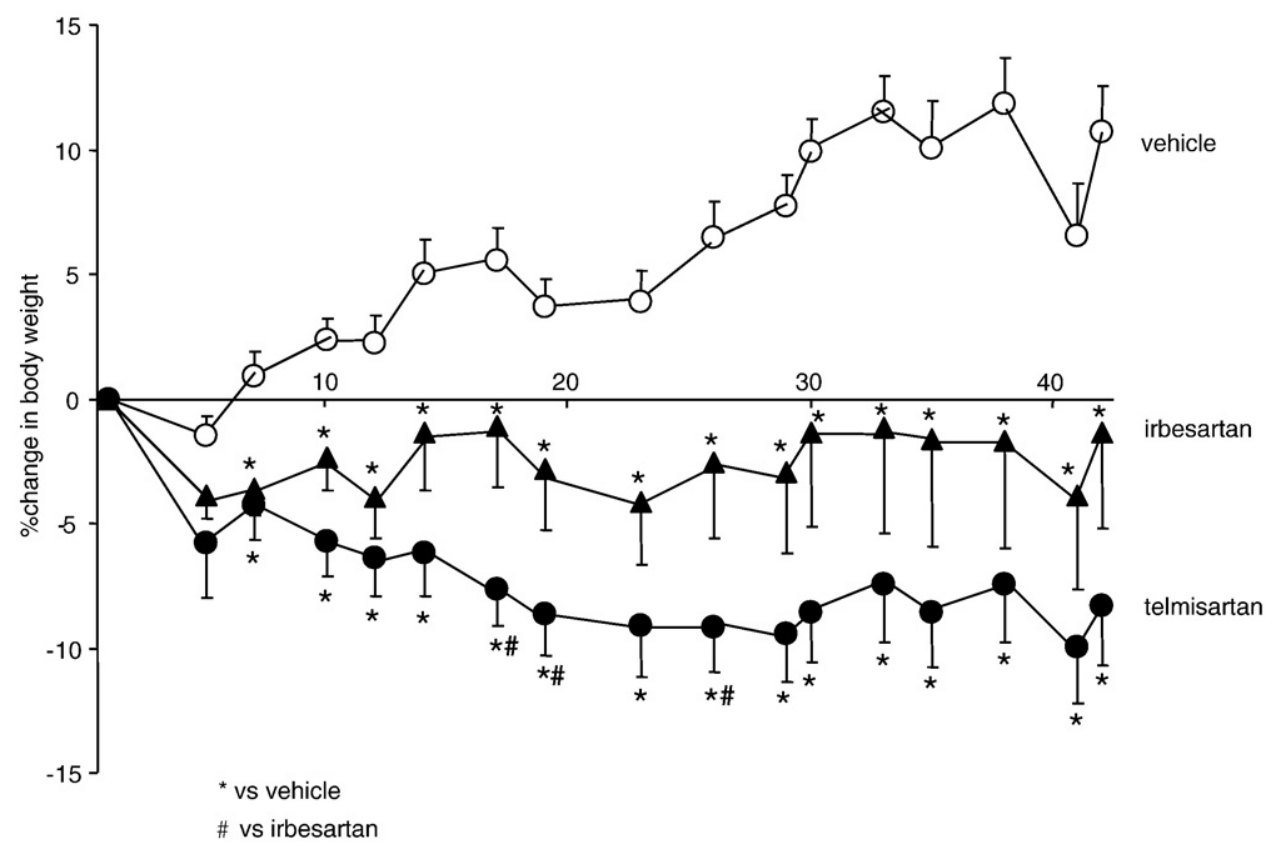

Fig. 2. Experiment 2: percentage change in body weight from baseline in vehicle-, irbesartan-, and telmisartan-treated mice. ${ }^{*} P<.05$. 


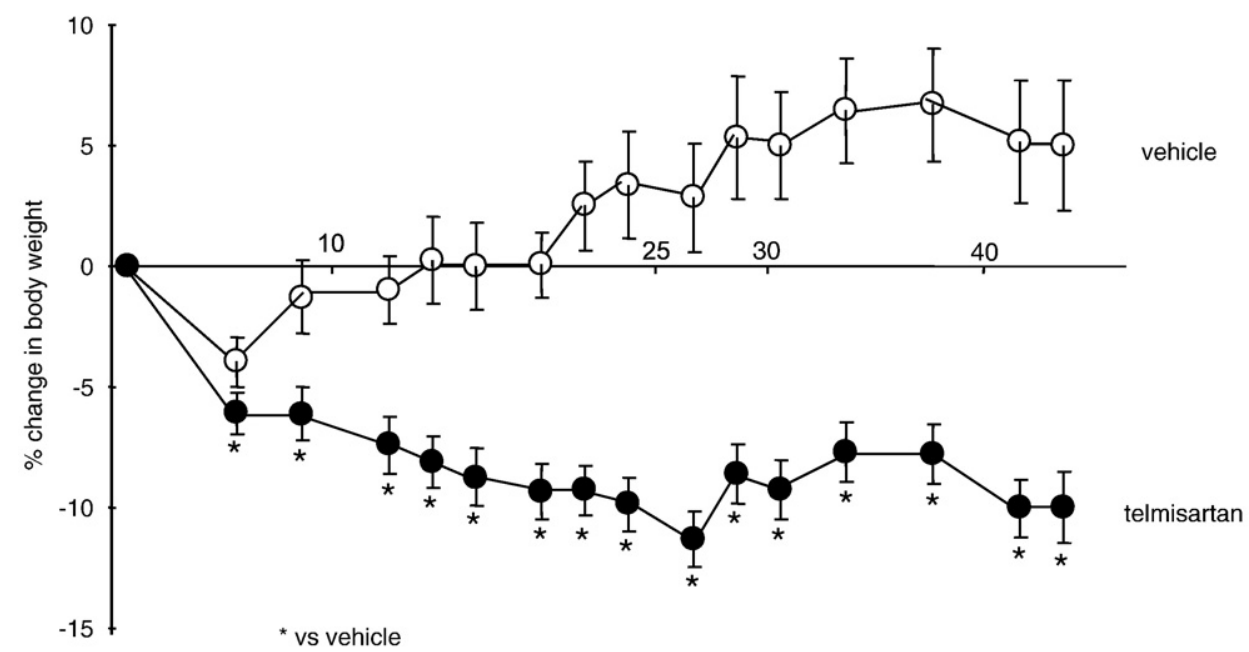

Fig. 3. Experiment 3: percentage change in body weight from baseline in vehicle- and telmisartan-treated AT- $1_{\mathrm{A}}$ receptor KO mice. ${ }^{*} P<.05$.

\subsection{Total kilometers achieved with running wheel}

Vehicle-treated mice ran $295.4 \pm 39.2 \mathrm{~km}$ and telmisartantreated mice ran $330.1 \pm 28.4 \mathrm{~km}$ over 25 days in their cages ( $P$ not significant).

\section{Discussion}

This study confirms that telmisartan has favorable effects on food intake, weight gain, and fat mass in rodents exposed to a high-fat diet and/or to a glitazone. It extends previous observations by demonstrating that these effects are independent from the angiotensin II $1_{\mathrm{A}}$ receptor. Although many mechanisms may be involved, the significant decrease in the expression of the orexigenic hypothalamic AgRP provides mechanistic insights into the anorexigenic properties of telmisartan.
The hypothalamus participates in a complex network of signals involved in the elaboration of orexigenic and anorexigenic signals. A well-recognized orexigenic neuromodulator is the AgRP, an endogenous antagonist of the melanocortin receptor, which interferes with the actions of the anorectic melanocyte-stimulating peptide encoded by the POMC gene. The AgRP is coexpressed with NPY within the hypothalamic arcuate neurons, and its expression is inhibited by adipocyte-released leptin and increased by food restriction. The AgRP expression or plasma levels have been associated with body weight. The expression is increased in mouse models of obesity [14], and plasma levels have been positively correlated to body mass index in humans [15]. In contrast, AgRP-deficient mice have an age-related lean phenotype and increased metabolic rate [16]. Corticosterone implants increase hypothalamic AgRP messenger RNA (mRNA) expression [17]. To our knowledge, no pharmacologic drug given orally has been shown to decrease AgRP expression in

Table 3

Body composition of mice at end of study

\begin{tabular}{|c|c|c|c|c|c|}
\hline & Dry weight & Water & Body fat & $\%$ Fat-free lean mass & $\%$ Fat \\
\hline \multicolumn{6}{|l|}{ Experiment 1} \\
\hline Vehicle & $11.2 \pm 0.9$ & $19.7 \pm 0.2$ & $5.45 \pm 0.8$ & $18.6 \pm 0.3^{\dagger}$ & $17.4 \pm 2.3$ \\
\hline Telmisartan & $9.1 \pm 0.8^{\dagger}$ & $18.2 \pm 0.5^{*, \dagger}$ & $3.77 \pm 0.7^{\dagger}$ & $19.6 \pm 0.4$ & $13.5 \pm 1.9^{*, \dagger}$ \\
\hline Pioglitazone & $13.6 \pm 0.7^{*}$ & $19.2 \pm 0.2$ & $7.9 \pm 0.7^{*}$ & $17.3 \pm 0.4^{\dagger}$ & $23.9 \pm 1.7$ \\
\hline $\begin{array}{l}\text { Pioglitazone- } \\
\text { telmisartan }\end{array}$ & $8.6 \pm 0.6^{* \dagger \dagger}$ & $18.2 \pm 0.3^{*, \dagger}$ & $3.45 \pm 0.5^{\dagger}$ & $19.4 \pm 0.4^{\dagger}$ & $12.6 \pm 1.5^{* \dagger \dagger}$ \\
\hline ANOVA & .001 & .007 & .001 & .001 & .001 \\
\hline \multicolumn{6}{|l|}{ Experiment 2} \\
\hline Vehicle & $16.2 \pm 1.3$ & $18.8 \pm 0.4$ & $9.2 \pm 1.1$ & $20.0 \pm 0.3$ & $25.9 \pm 1.7$ \\
\hline Irbesartan & $12.7 \pm 1.3^{*}$ & $17.8 \pm 0.3^{*}$ & $6.2 \pm 1.1^{*}$ & $21.5 \pm 0.6^{*}$ & $19.3 \pm 2.7^{*}$ \\
\hline Telmisartan & $10.8 \pm 0.4^{*}$ & $17.4 \pm 0.2^{*}$ & $4.5 \pm 0.4^{*}$ & $22.4 \pm 0.3^{*}$ & $15.9 \pm 1.0^{*}$ \\
\hline ANOVA & .007 & .02 & .006 & .008 & .008 \\
\hline
\end{tabular}

${ }^{*} P<.05$ vs vehicle.

${ }^{\dagger} P<.05$ vs pioglitazone. 


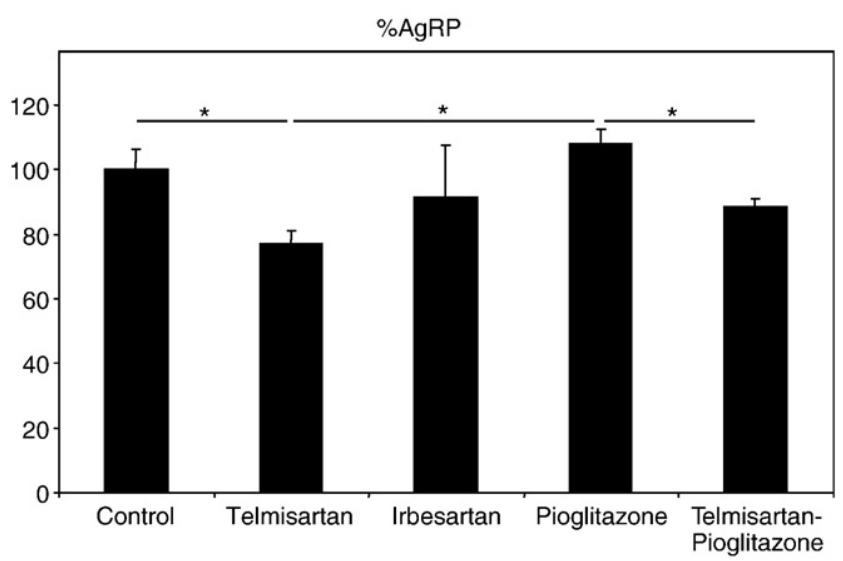

Fig. 4. Experiments 1 and 2: mRNA expression of AgRP in comparison with controls $(100 \%) . * P<.05$.

mice. Our study demonstrates for the first time a significant influence of the orally administered angiotensin II receptor blocker telmisartan on the hypothalamic expression of AgRP.

Because experimental studies show that stress can decrease the expression of the AgRP mRNA expression in arcuate nucleus neurons [18], we wanted to exclude a deleterious effect of telmisartan on the well-being of mice. Mice treated with telmisartan ran a slightly longer distance using running wheel than vehicle-treated mice, suggesting that the general condition of these mice was satisfactory. Interestingly, a study showed that AgRP-deficient mice have an increase in their spontaneous physical activity [16]. Whether the telmisartan-induced decrease in the expression of the AgRP influenced independently and directly the food intake and spontaneous physical activity still needs further investigations.

In this study, other central neuroendocrine factors were not involved such as POMC or NPY. Neuropeptide Y and AgRP are coexpressed in hypothalamic arcuate neurons and respond similarly to food deprivation and leptin administration. In our study, telmisartan-induced changes in AgRP and NPY did not parallel, suggesting a differential regulation of both peptides in this particular experimental setting. In agreement with our observations, recent studies demonstrated that there may be a differential expression of both peptides, as during stress or short photoperiod $[18,19]$. In contrast to AgRP changes, the
NPY response in the pioglitazone-telmisartan group was similar to that observed as a consequence of food deprivation, weight loss, and decreased leptin levels. Therefore, the anorexigenic properties of telmisartan could result from a decrease in the expression of the AgRP that is other than or beyond NPY modulation.

One study demonstrated that telmisartan has a favorable effect on weight gain by decreasing food intake in addition to increasing energy expenditure and brown adipose tissue uncoupling protein 1 (UCP-1) expression [20]. Another study showed that the intracerebroventricular administration of AgRP results in an increase in food intake and a decrease in brown adipose tissue UCP-1 expression [21]. The decrease in the hypothalamic expression of the AgRP found in our study may be the common pathway resulting in both favorable effects of telmisartan on brown adipose tissue UCP-1 expression and food intake.

Rodents express 2 isoforms of the AT- 1 receptor (AT- $1_{\mathrm{A}}$ and $\mathrm{AT}-1_{\mathrm{B}}$ ), which are highly homologous and inhibited by angiotensin II receptor antagonists. The expression of the AT- $1_{\mathrm{A}}$ receptor in the brain exceeds that of the AT- $1_{\mathrm{B}}$ receptor. Importantly, the telmisartan-induced decrease in food intake was associated with a significant increase in water intake in wild-type and in $\mathrm{AT}-\mathrm{1}_{\mathrm{A}}$ receptor $\mathrm{KO}$ mice, which excludes an aversion to telmisartan in drinking water as the cause of the decreased food intake. Interestingly, in vehicle-treated mice, water intake was not decreased in AT- $1_{\mathrm{A}}$ receptor KO mice compared with wild-type mice. These results are in contradiction with the findings that the overexpression of brain $\mathrm{AT}-\mathrm{1}_{\mathrm{A}}$ receptors increases water intake and that some angiotensin II receptor antagonists (irbesartan and losartan) decrease water intake [22-24]. We cannot exclude that the measured increase in water intake may have been biased by a higher spillage due to a higher activity of the telmisartan-treated mice and playing with water bottles. Neither can we exclude that the higher water intake may have increased energy expenditure, although this possible interaction has recently been questioned [25]. Although controversial and poorly studied, we cannot exclude an influence of the larger fluid intake on decreased food intake in this model. However, if increased drinking behavior was the main cause of decreased food intake, the consequent food deprivation would have been associated with an increase in hypothalamic AgRP expression, which was not the case.

Table 4

Plasma leptin levels and hypothalamic mRNA levels of peptides implicated in food intake control (experiment 1)

\begin{tabular}{lccc}
\hline Group & Leptin $(\mathrm{ng} / \mathrm{mL})$ & NPY $(\%$ vehicle $)$ & POMC $(\%$ vehicle) \\
\hline Vehicle & $7.1 \pm 1.4$ & $100 \pm 9.05$ & $100 \pm 13.71$ \\
Telmisartan & $5.2 \pm 1.5$ & $92.1 \pm 5.53$ & $87.1 \pm 6.31$ \\
Pioglitazone & $12.9 \pm 2.3$ & $91.8 \pm 12.72$ & $100 \pm 7.60$ \\
Pioglitazone-telmisartan & $4.2 \pm 1.1^{\dagger}$ & $184.6 \pm 28.9^{*},{ }^{\dagger}$ & $109.4 \pm 18.39$ \\
ANOVA & .005 & .002 & $158.8 \pm 39.67$ \\
\end{tabular}

$* P<.05$ vs vehicle.

$\dagger P<.05$ vs pioglitazone. 
The fact that the anorexigenic properties of telmisartan were still present in AT- $1_{\mathrm{A}}$ receptor $\mathrm{KO}$ mice suggests that some actions of telmisartan are not mediated by the AT- $1_{\mathrm{A}}$ receptor in accordance with the AT-1 receptor-independent PPAR- $\gamma$ properties of telmisartan [5]. However, this study cannot exclude a possible central effect of telmisartan on the AT- $1_{\mathrm{B}}$ receptor.

Pioglitazone induced a rapid and sustained increase in body weight. Although fluid retention has been demonstrated with pioglitazone after 6 days of treatment [26], longterm treatment (6 weeks) in our study did not demonstrate any fluid retention but an increase in fat mass. Pioglitazone was only associated with a slight but nonsignificant increase in food intake in this model, in contrast to the marked pioglitazone-induced hyperphagia we observed previously in the Zucker rat model of obesity [9]. No modification of central neuroendocrine factors was demonstrated with pioglitazone in this study or in the Zucker rat model (data not shown). Only leptin was increased with pioglitazone and was overall very strongly correlated to percentage fat composition $\left(R^{2}=89.1 \%, P<.001\right)$. This study shows that the effects of telmisartan on pioglitazone-induced changes in body composition in mice are pronounced without changing the insulin-sensitizing properties of pioglitazone, as we already demonstrated previously in rat models of obesity [9]. These effects are strongly mediated through the decreased food intake; however, an influence of telmisartan on pioglitazone-induced adipogenesis or on energy expenditure is not excluded.

The mechanisms of body weight regulation are complex, involving both central and peripheral signals modulating caloric intake and total energy expenditure. In addition, some drugs can increase fat mass, particularly the powerful insulin sensitizers and PPAR- $\gamma$ agonists pioglitazone and rosiglitazone. Telmisartan has unique properties beyond its angiotensin II antagonistic effects. This study confirms the anorexigenic effects of telmisartan in mice treated with a glitazone and/or fed a high-fat diet and suggests that the effect is AT- $1_{\mathrm{A}}$ receptor independent and is mediated through a decrease in the neuroendocrine orexigenic modulator AgRP. In this study, irbesartan had favorable effects on weight gain and on the expression of the AgRP that were intermediate to telmisartan. Further studies are needed to explore in more details the neuroendocrine effects of these angiotensin II receptor blockers, in particular by examining which signaling pathways are involved and whether they depend on their selective PPAR- $\gamma$ modulating activity. If these observations are confirmed in clinical trials, the use of telmisartan may be an interesting option to regulate dietinduced and glitazone-induced weight gain.

\section{References}

[1] Maillard MP, Perregaux C, Centeno C, Stangier J, Wienen W, Brunner $\mathrm{HR}$, et al. In vitro and in vivo characterization of the activity of telmisartan: an insurmountable angiotensin II receptor antagonist. J Pharmacol Exp Ther 2002;302:1089-95.

[2] Sharma AM. Telmisartan: the ACE of ARBs? Hypertension 2006;47: 822-3.

[3] Benson SC, Pershadsingh HA, Ho CI, Chittiboyina A, Desai P, Pravenec $\mathrm{M}$, et al. Identification of telmisartan as a unique angiotensin II receptor antagonist with selective PPARgamma-modulating activity. Hypertension 2004;43:993-1002.

[4] Schupp M, Clemenz M, Gineste R, Witt H, Janke J, Helleboid S, et al. Molecular characterization of new selective peroxisome proliferatoractivated receptor \{gamma\} modulators with angiotensin receptor blocking activity. Diabetes 2005;54:3442-52.

[5] Schupp M, Janke J, Clasen R, Unger T, Kintscher U. Angiotensin type 1 receptor blockers induce peroxisome proliferator-activated receptor-gamma activity. Circulation 2004;109:2054-7.

[6] Benndorf RA, Rudolph T, Appel D, Schwedhelm E, Maas R, Schulze $\mathrm{F}$, et al. Telmisartan improves insulin sensitivity in nondiabetic patients with essential hypertension. Metabolism 2006;55:1159-64.

[7] Nagel JM, Tietz AB, Goke B, Parhofer KG. The effect of telmisartan on glucose and lipid metabolism in nondiabetic, insulin-resistant subjects. Metabolism 2006;55:1149-54.

[8] Ichikawa Y. Comparative effects of telmisartan and valsartan on insulin resistance in hypertensive patients with metabolic syndrome. Intern Med 2007;46:1331-6.

[9] Zanchi A, Dulloo AG, Perregaux C, Montani JP, Burnier M. Telmisartan prevents the glitazone-induced weight gain without interfering with its insulin-sensitizing properties. Am J Physiol Endocrinol Metab 2007;293:E91-5.

[10] Sugimoto K, Qi NR, Kazdova L, Pravenec M, Ogihara T, Kurtz TW. Telmisartan but not valsartan increases caloric expenditure and protects against weight gain and hepatic steatosis. Hypertension 2006;47: 1003-9.

[11] Entenman C. General procedures for separating components of tissue. In: Colowick SP, Kaplan O, editors. Methods in enzymology. New York: Academic; 1957:299-317.

[12] Dulloo AG, Girardier L. Adaptive changes in energy expenditure during refeeding following low-calorie intake: evidence for a specific metabolic component favoring fat storage. Am J Clin Nutr 1990;52: 415-20.

[13] Ye F, Tao R, Cong W, Tian J, Liu Q. Utilization of fluorescence tracer in hyperinsulinemic-euglycemic clamp test in mice. J Biochem Biophys Methods 2008;70:978-84.

[14] Shutter JR, Graham M, Kinsey AC, Scully S, Luthy R, Stark KL. Hypothalamic expression of ART, a novel gene related to agouti, is upregulated in obese and diabetic mutant mice. Genes Dev 1997;11: 593-602.

[15] Katsuki A, Sumida Y, Gabazza EC, Murashima S, Tanaka T, Furuta M, et al. Plasma levels of agouti-related protein are increased in obese men. J Clin Endocrinol Metab 2001;86:1921-4.

[16] Wortley KE, Anderson KD, Yasenchak J, Murphy A, Valenzuela D, Diano S, et al. Agouti-related protein-deficient mice display an agerelated lean phenotype. Cell Metab 2005;2:421-7.

[17] Makimura H, Mizuno TM, Isoda F, Beasley J, Silverstein JH, Mobbs CV. Role of glucocorticoids in mediating effects of fasting and diabetes on hypothalamic gene expression. BMC Physiol 2003; 3:5.

[18] Kas MJ, Bruijnzeel AW, Haanstra JR, Wiegant VM, Adan RA. Differential regulation of agouti-related protein and neuropeptide $\mathrm{Y}$ in hypothalamic neurons following a stressful event. J Mol Endocrinol 2005;35:159-64.

[19] Mercer JG, Moar KM, Ross AW, Hoggard N, Morgan PJ. Photoperiod regulates arcuate nucleus POMC, AGRP, and leptin receptor mRNA in Siberian hamster hypothalamus. Am J Physiol Regul Integr Comp Physiol 2000;278:R271-81.

[20] Araki K, Masaki T, Katsuragi I, Tanaka K, Kakuma T, Yoshimatsu H. Telmisartan prevents obesity and increases the expression of uncoupling protein 1 in diet-induced obese mice. Hypertension 2006;48:51-7. 
[21] Small CJ, Kim MS, Stanley SA, Mitchell JR, Murphy K, Morgan DG, et al. Effects of chronic central nervous system administration of agouti-related protein in pair-fed animals. Diabetes 2001;50: 248-54.

[22] Culman J, von Heyer C, Piepenburg B, Rascher W, Unger T. Effects of systemic treatment with irbesartan and losartan on central responses to angiotensin II in conscious, normotensive rats. Eur J Pharmacol 1999; 367:255-65.

[23] Davisson RL, Oliverio MI, Coffman TM, Sigmund CD. Divergent functions of angiotensin II receptor isoforms in the brain. J Clin Invest 2000;106:103-6.
[24] Lazartigues E, Sinnayah P, Augoyard G, Gharib C, Johnson AK, Davisson RL. Enhanced water and salt intake in transgenic mice with brain-restricted overexpression of angiotensin (At1) receptors. Am J Physiol Regul Integr Comp Physiol 2008.

[25] Brown CM, Dulloo AG, Montani JP. Water-induced thermogenesis reconsidered: the effects of osmolality and water temperature on energy expenditure after drinking. J Clin Endocrinol Metab 2006;91:3598-602.

[26] Guan Y, Hao C, Cha DR, Rao R, Lu W, Kohan DE, et al. Thiazolidinediones expand body fluid volume through PPARgamma stimulation of ENaC-mediated renal salt absorption. Nat Med 2005;11: 861-6. 